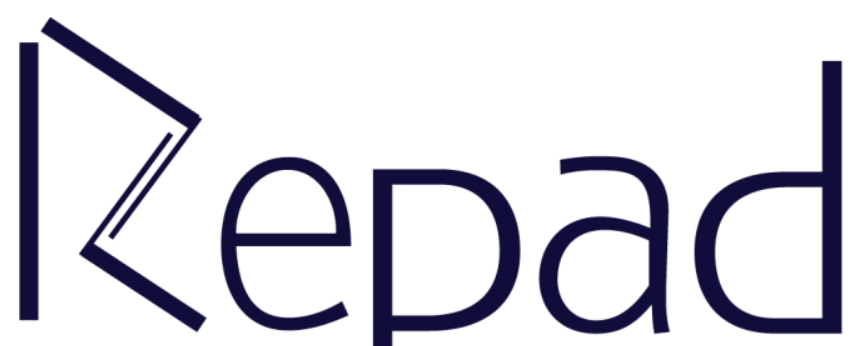

v. 5 , n. 2, Maio-Agosto/2021

Revista Estudos e

Pesquisas em Administração

(cC) (i) This work is licensed under a Creative Commons Attribution 4.0 International License 


\title{
ENTENDIMENTO DAS OPINIÕES DOS VAREJISTAS COM INTERVENÇÃO DE GERENCIAMENTO DE CATEGORIA EM PAPELARIAS
}

\author{
Marcos Bechert Sartori \\ marcosdrh@hotmail.com \\ Orcid - 0000-0002-7406-6550 \\ Lattes - http://lattes.cnpq.br/4125493129991780 \\ Fundação Getúlio Vargas - EAESP \\ São Paulo, São Paulo, Brasil
}

\begin{abstract}
Resumo
Um dos grandes desafios do pequeno varejo brasileiro é ter acesso a técnicas de gestão do espaço físico das lojas, em virtude do custo de oportunidade do uso do limitado espaço entre produtos que competem entre si por visibilidade. Iniciativas de Gerenciamento de Categorias podem suprir parte desta demanda, e facilitar a interação entre varejista e indústria, através da troca de informações e do incremento dos resultados. O objetivo deste estudo foi verificar se uma alteração no modelo de exposição da categoria de papel em seis papelarias resultaria em mudança na percepção dos lojistas acerca do novo layout e dos materiais de exposição e comunicação da categoria nas suas papelarias. Os resultados confirmam que as intervenções executadas impactaram positivamente a opinião dos varejistas que participaram do piloto. Foi possível identificar que a categoria de papel não tinha padrão de exposição nem estratégia de comunicação dentro das lojas. Foi possível criar um plano de exposição e comunicação eficientes, que valorizaram a categoria e consequentemente agregaram valor as lojas participantes.
\end{abstract}

Palavras- Chave: Gerenciamento de categorias. Alocação de espaço. Varejo. Categoria de papel.

\section{UNDERSTANDING OF RETAILERS' OPINIONS WITH CATEGORY MANAGEMENT INTERVENTION IN STATIONARY SHOPS}

\begin{abstract}
One of the great challenges of small retail in Brazil is to access technics for managing the physical store space, due to the opportunity cost of using the limited space. Category management initiatives can solve part of this demand, facilitating interaction between retailer and industry, through the exchange of information and increased results. The aim of this study was to verify whether a change in the paper category exposure model in six stationary shops would result in a perception change of shopkeepers about the new layout and the exhibition and communication materials for the category. The results confirm that the interventions positively impacted on the retailers' perception which participated in the pilot. It was possible to identify that the paper category had no exposure pattern or communication strategy within the stores. It was possible to create an efficient exhibition and communication plan, which added value to the participating stores.
\end{abstract}

Keywords: Category management. Space allocation. Retail. Stationery category.

Submetido: $11 / 11 / 2020$

Revisões Requeridas: 13/03/2021 
Aceito: $24 / 07 / 2021$

\section{INTRODUÇÃO}

Publicado: $31 / 08 / 2021$

O fortalecimento da colaboração entre o varejo e a indústria começou a ocorrer nos Estados Unidos no final da década de 80 e início da década de 90 por meio do Efficient Consumer Response (ECR), em português: Resposta Eficiente ao Consumidor. O ECR tem como fundamento o aprimoramento do fluxo de informação entre os elos da cadeia de suprimentos (GHISI; SILVA, 2008). Uma das principais ferramentas oriundas do ECR para se operacionalizar esse fluxo de informações se dá por um processo colaborativo entre a indústria e o varejo chamado Gerenciamento de Categoria (GC).

De acordo com a definição da Nielsen (1992), GC é um processo realizado por distribuidores/fabricantes que envolve gerenciar cada categoria de produtos como uma unidade de negócios, customizando-a loja a loja para satisfazer as necessidades do consumidor. Todo processo de GC tem como premissa o estabelecimento de uma relação de confiança entre o fornecedor e o varejista. Ainda que o varejista tenha os recursos suficientes para implantar e gerenciar um projeto desta natureza, traz mais resultados quando o trabalho é feito de maneira colaborativa com a indústria, especialmente se for a indústria líder da categoria a escolhida para capitanear o processo (Category Captain) (GOONER; MORGAN PERREAULT, 2011). Nas relações transacionais, as partes envolvidas não estão interessadas em estabelecer uma relação de longo-prazo, ou seja, a cada transação os termos são negociados e na maioria das vezes, especialmente em mercados de commodities, o fator preço e condições de pagamento são o foco da negociação. Já nas transações relacionais, o conjunto de serviços e benefícios oferecidos pelas partes tem mais peso do que simplesmente o fator preço, beneficiando a relação a longo prazo.

A implantação de um processo de GC traz oportunidade para ambos elos da cadeia: a indústria, por meio do melhor aproveitamento da área de vendas da loja e para o varejista, podendo aproveitar o conhecimento da indústria para trabalhar de maneira profissional as suas diversas categorias de produtos, com o melhor posicionamento de espaço e preço, de maneira a atrair e fidelizar seu shopper, aumentando as receitas da loja (GUISSONI; CONSOLI; CASTRO, 2010).

Já são observados avanços na literatura envolvendo práticas de GC no pequeno varejo de autosserviços do ramo alimentício. Um estudo conduzido por Guissoni, Consoli e Rodrigues (2013), aprofundou ainda mais os estudos desta temática, inserindo pequenos autosserviços independentes, denominados supermercados de bairro cuja gestão e propriedade são familiares, em um contexto de GC. Os resultados garantiram a indústria melhora nos indicadores de sell out e market share nas lojas que participaram do experimento e possibilitando aos pequenos varejistas terem acesso a uma nova ferramenta de gestão. Entretanto, o varejo de papelarias ainda não tinha sido objeto de estudo. A categoria de papel é considerada como categoria destino e é responsável por até $30 \%$ do faturamento global da loja, segundo as informações obtidas com as entrevistas exploratórias realizadas com os proprietários das lojas participantes do piloto.

O objetivo deste estudo foi, através de um piloto, verificar se uma alteração no modelo de exposição da categoria de papel resultaria em uma alteração na opinião dos lojistas participantes acerca do novo layout e dos materiais que foram utilizados para fazer a exposição e comunicação da categoria. Também foram coletados outros aspectos 
da categoria de papel, como: a relevância para o segmento, insights sobre a exposição, visão do shopper e da indústria. As respostas foram obtidas por meio de entrevistas (pesquisa exploratória), realizadas antes e depois do piloto com os proprietários das lojas participantes. Ao analisar as papelarias participantes do piloto, pode-se notar que não existia um padrão específico para organização da categoria de papel nas lojas. Os diversos tipos de papéis (sulfite, fotográfico, coloridos e outros formatos) estavam todos alocados de maneira dispersa, sem um ponto natural. Também não havia identidade visual definida, existiam alguns displays para expor os produtos de marcas específicas, mas nada que caracterizasse a categoria como um todo. Outro aspecto importante é que não existia um sortimento padrão, cada loja tinha marcas diferentes e muitas vezes com posicionamentos concorrentes no mesmo nicho de mercado.

Na prática, as indústrias fornecedoras do segmento de papelarias, especialmente na categoria de papel são historicamente muito "distantes" dos varejistas. Não se observam esforços contínuos da indústria no ponto de venda para construir relacionamento, logo, a maioria das relações são puramente transacionais e sem geração de valor para ambos os lados (modelo ganha-perde). Isso em parte se explica pelo fato de que a concorrência no segmento de papel sulfite é desfavorável para o varejista, pois existem praticamente só dois grandes fornecedores no Brasil.

Uma das principais razões desta falta de padronização é que o setor de papelarias no Brasil é caracterizado por pequenas lojas geridas de maneira familiar. Apesar de todo movimento de fusões e aquisições que o Brasil vivenciou nos anos 2000, em alguns segmentos de varejo, como alimentício e farmácias, esse setor não passou por grandes transformações, ou seja, salvo algumas raras exceções, ele funciona quase da mesma maneira que funcionava no seu surgimento. No Brasil existem mais de seis mil papelarias considerando todos os portes, sendo $97 \%$ delas micro e pequenas empresas. Isso demonstra que o cenário para as pequenas papelarias é cada vez mais desafiador, de um lado o e-commerce que vem ganhando cada vez mais força e que opera por meio de redes de varejo como o Submarino, Americanas, Magazine Luiza e Amazon, que funcionam também como grandes canais de marketplace e em alguns casos possuem até lojas físicas. De outro lado precisam enfrentar a concorrência de redes (i.e.Kalunga), com um modelo de gestão profissional e que está em plena expansão. Outro fator a ser levado em conta, é a venda direta da indústria para o shopper corporativo (B2B), por meio de uma central de vendas. Algumas papelarias, inclusive uma das participantes do piloto, já vem tentando se adaptar a esse novo mercado e criou um canal de vendas que está sendo explorado nos principais marketplaces.

Um projeto de Gerenciamento de Categorias pode auxiliar esse segmento na busca pela sobrevivência da loja física e do seu modelo de negócio, tornando o ambiente de loja e a experiência de compra mais agradáveis ao shopper, tendo em vista que o cenário de concorrência está cada vez mais árduo e dinâmico. A questão de pesquisa que o piloto buscou responder foi se uma alteração do modelo de exposição da categoria de papel alterar a opinião do varejista sobre a categoria nas papelarias participantes do piloto.

\section{REVISÃO DE LITERATURA}

O referencial teórico deste estudo é fundamentado segundo os tópicos a seguir: Conceito de Gerenciamento de Categorias (GC); Definição de categoria de produtos; Definição dos Agentes envolvidos em um plano de GC; Intervenções propostas em um 
plano de GC com foco na intervenção do experimento - Alocação de Espaço; Conceito de Cross-category management.

\section{ECR e Gerenciamento de Categoria - Conceitos}

Os estudos que precedem o Gerenciamento de Categorias surgiram através do conceito de ECR - Efficient Consumer Response, criado no início da década de 1990 por meio de uma parceria entre a indústria Procter \& Gamble com a grande rede varejista Wal-Mart nos EUA. O conceito de ECR foi evoluindo ao longo dos anos, porém ele se baseia em três pilares baseados num processo de colaboração entre a indústria e varejo: (i) gestão da demanda, ou seja, promoção de atividades conjuntas de marketing e vendas para estimular a demanda; (ii) gestão da oferta, otimizar o fornecimento com foco em suprimentos e logística integrada; (iii) implantar e compartilhar informação entre as partes para suportar o processo decisório. Atuando de maneira cooperada, fabricantes e varejistas podem melhorar a experiência de compra dos clientes, com mais rapidez e de forma mais barata (CORSTEN; KUMAR, 2005).

O grande motivador para a criação desse conjunto de iniciativas de colaboração foi o crescimento do ambiente de competição e compressão das margens que todos os agentes econômicos vem enfrentando, principalmente a partir da década de 1990, com a globalização dos mercados, o movimento de fusões e aquisições que criaram gigantes em todos os segmentos (ARKADER; FERREIRA, 2004). Esse ambiente fez surgir a necessidade da colaboração como premissa de sobrevivência e manutenção da competitividade para os varejistas e indústrias, levando-os a sair de um modelo puramente transacional, para um modelo de construção de parcerias com visão de longo prazo.

Uma das principais ferramentas que surgiram para responder essas iniciativas foi o Gerenciamento de Categorias, que surge para fortalecer a colaboração entre os agentes - indústria e varejo, de maneira sistemática e organizada, englobando os três pilares de um processo de ECR. Dentre as diversas razões para implantar um processo de gerenciamento de categorias, a principal é a vontade da indústria e varejo em desenvolver objetivos comuns para o seu negócio, com foco em entregar mais valor para o consumidor (Category Management Report, 1995). Mais do que isso, a força motriz que leva a um processo de GC é a necessidade dos varejistas se diferenciarem dos concorrentes, a pressão de lidar com a proliferação de novos produtos surgindo a todo momento e tentar fazer o melhor trade-off possível (a variável espaço de gôndola limita o mix) e ainda maximizar receita e rentabilidade (NIELSEN, 1992).

Segundo Dussart (1998), um processo de GC envolve uma quebra de paradigma na maneira de enxergar e gerenciar os produtos dentro da loja, de uma visão de gerenciamento de marca (muito comum na década de 1970 e 1980), para uma visão de categoria. O cerne da questão é entender que uma categoria de produtos geralmente envolve uma decisão de substituição e complementariedade. Logo, faz sentido que o varejista/indústria comece a enxergar seus produtos num contexto de categoria e não mais por marca/fabricante, buscando potencializar cada produto modo a convergir para um objetivo comum.

Definir essa hierarquia de mix de produtos, partindo desde a definição das macro áreas até o micro gerenciamento por subsegmentos, passando pela definição das categorias, não é uma tarefa simples e envolve bastante discussões entre indústria e varejo. Um dos pontos sugeridos pela literatura como determinantes no sucesso de uma 
iniciativa de GC é a colaboração, numa relação ganha-ganha prevaleça sobre as possíveis desavenças (DUSSART, 1998).

Figura 1. Diagrama da Estrutura de Mix de Produtos de um Varejista

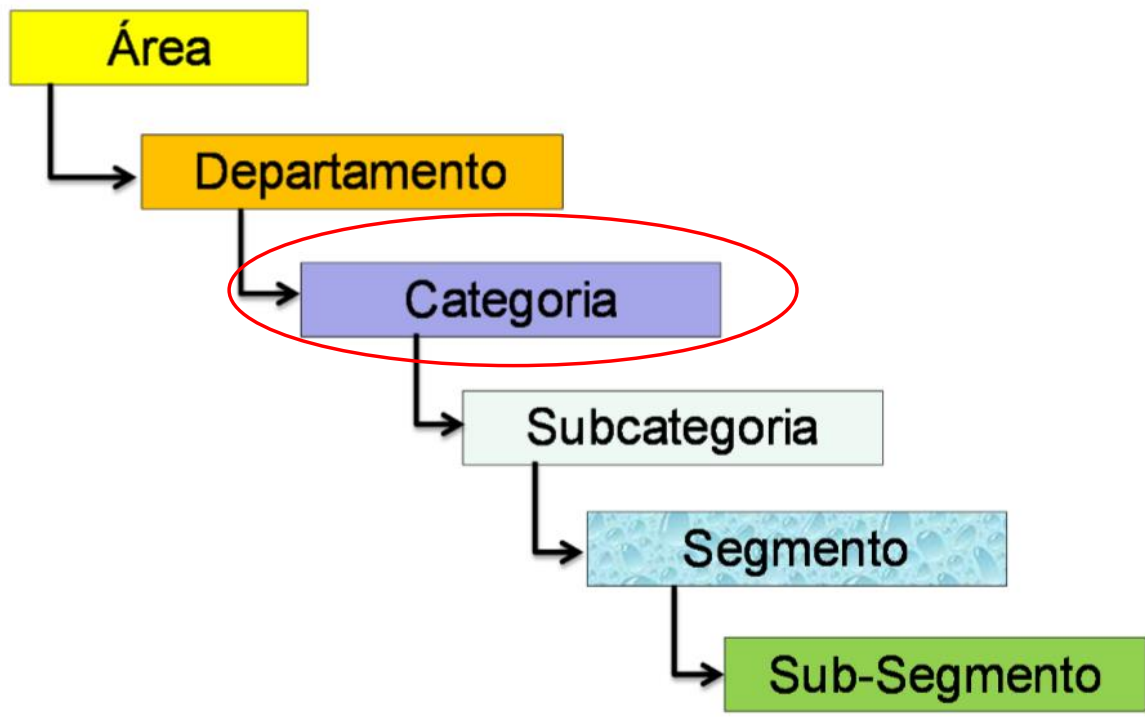

Fonte. Parente e Barki (2014, p. 16)

A implantação de um processo completo de GC envolve diversas etapas. No Brasil, o modelo mais disseminado é o proposto pela ECR Brasil (1998):

Figura 2. Etapas de um processo de Gerenciamento por Categoria

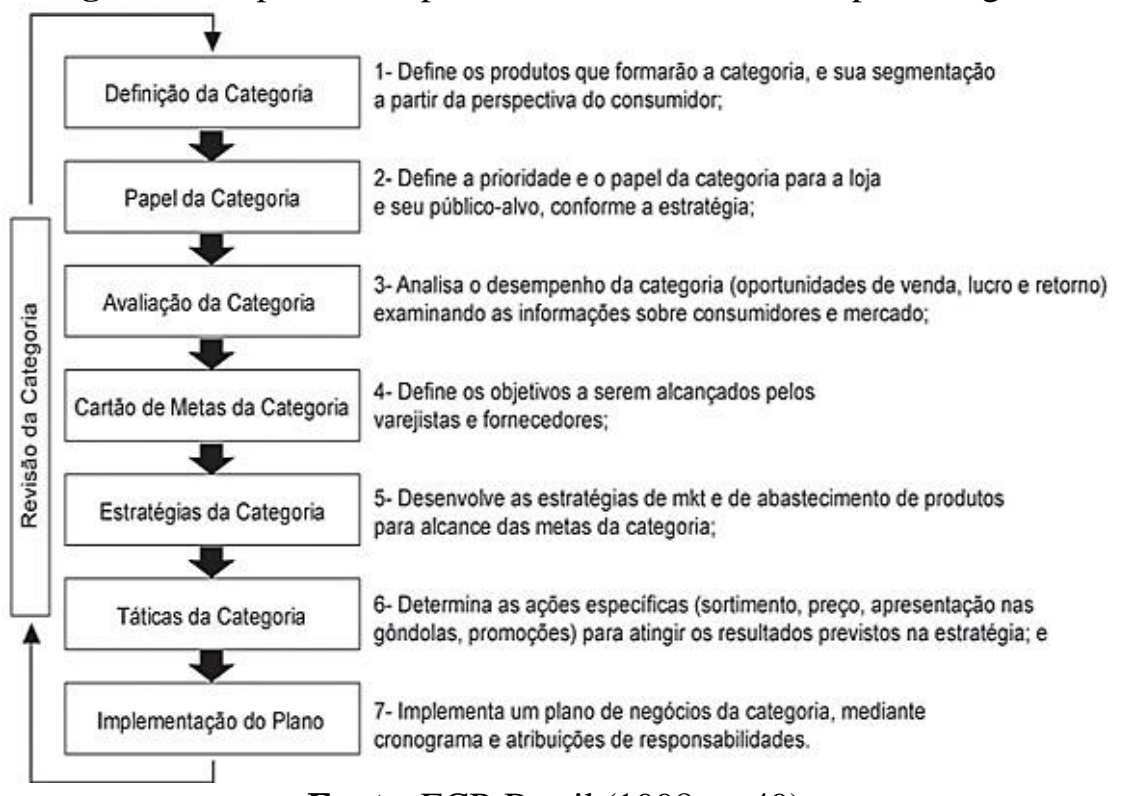

Fonte. ECR Brasil (1998, p. 49)

Cada uma das etapas acima tem papel estratégico na formulação de um processo de GC. É importante notar que o ciclo se retroalimenta, como um sistema dinâmico de aperfeiçoamento que deve ser avaliado com frequência, a fím de um melhor aproveitamento. 


\section{Definição das categorias de produtos}

Cada uma das categorias tem um papel específico que pode variar de acordo com as características do ponto de venda. Por exemplo, uma papelaria geralmente tem o papel sulfite dentro da categoria destino. Esse mesmo produto em um grande autosserviço pode ser associado a uma categoria de conveniência. A seguir a definição dos quatro papéis principais de cada categoria, segundo Parente e Barki (2014), e como o papel sulfite pode assumir diferentes atribuições durante a jornada de compra do shopper:

- Categoria de Destino: É lembrada pelos consumidores como atração para irem até aquele ponto de venda, aquele segmento ou ponto de venda é reconhecido como a melhor opção dentre os concorrentes que vendem essa categoria. Muita alta capacidade de atrair clientes e de firmar o posicionamento do varejista. O papel sulfite é considerado como categoria de destino nas papelarias, pois ele é um dos itens de maior peso na cesta de compras do setor e tem uma grande frequência de compras. Geralmente, os shoppers de maior frequência, escolhem onde vão fazer as compras dos produtos de papelaria no local que tiver as melhores condições no papel sulfite

- Categoria de Rotina: São os produtos que o shopper consome com regularidade, rotineiros. Tem capacidade de atrair o shopper, porém não a ponto de ser o objetivo fim da ida a determinado ponto de venda. Podem ser confundidos com os produtos da categoria de conveniência e possuem alta capacidade de atrair clientes. Dificilmente o papel sulfite assume essa característica, mesmo sendo um item de consumo rotineiro, como explicado no item anterior.

- Categoria de Conveniência: São categorias que o shopper despende pouco esforço na hora da escolha e podem ser considerados produtos adquiridos adicionalmente aos principais. Mas ainda assim, ter essa variedade da a loja uma sensação de ser completa e atender toda a necessidade do consumidor. Baixa capacidade de atrair clientes. O papel sulfite em um autosserviço pode assumir essa característica, isso pode ocorrer quando o shopper vai até esse canal buscando comprar outros produtos, principalmente do ramo alimentício e acaba levando o papel sulfite para atender a sua necessidade, pois ele não quer fazer o esforço de ir até outro ponto de venda (uma papelaria, por exemplo), para adquirir só uma resma de papel.

- Categoria de Produtos Ocasionais (Sazonais): São categorias de produtos que geralmente são consumidos em épocas e situações específicas. É importante que o ponto de venda tenha essas categorias para aproveitar as vendas durante a sazonalidade. Média capacidade de atrair clientes. Neste caso o papel sulfite assume essa característica durante a maior sazonal de vendas da categoria, como o varejo de volta as aulas (denominação como o período é conhecido no setor) em outros setores de varejo, como lojas de departamento (Americanas, por exemplo) e também autosserviços, onde ele deixa de assumir papel de produto de conveniência para ser um produto Sazonal, com grande 
incremento de vendas no período, ganhando grande destaque na exposição.

Uma sugestão aos agentes envolvidos num processo de GC é que sejam capazes de definir claramente o papel de cada categoria e então concentrar os esforços nas categorias chave a fim de obterem os melhores resultados para ambos. A partir da definição de cada categoria e seu papel dentro do ponto de venda, são executadas as próximas etapas de implantação. O caso específico do papel sulfite, por exemplo, mostra como um mesmo produto pode assumir diferentes papéis que variam principalmente em função do setor em que esta inserido (papelaria, autosserviço, loja de departamento).

\section{Agentes de um processo GC e os benefícios para cada um}

Em um processo de Gerenciamento de Categorias, temos três elos que definem sua estrutura: Indústrias (Manufacturers); Varejistas/Lojistas (Retailers); Consumidores (Shoppers) (HAMISTER; FORTSCH, 2016). A seguir a definição de cada papel.

Figura 3. Descrição dos três agentes que compõe um programa de Gerenciamento de

$$
\text { Categorias }
$$

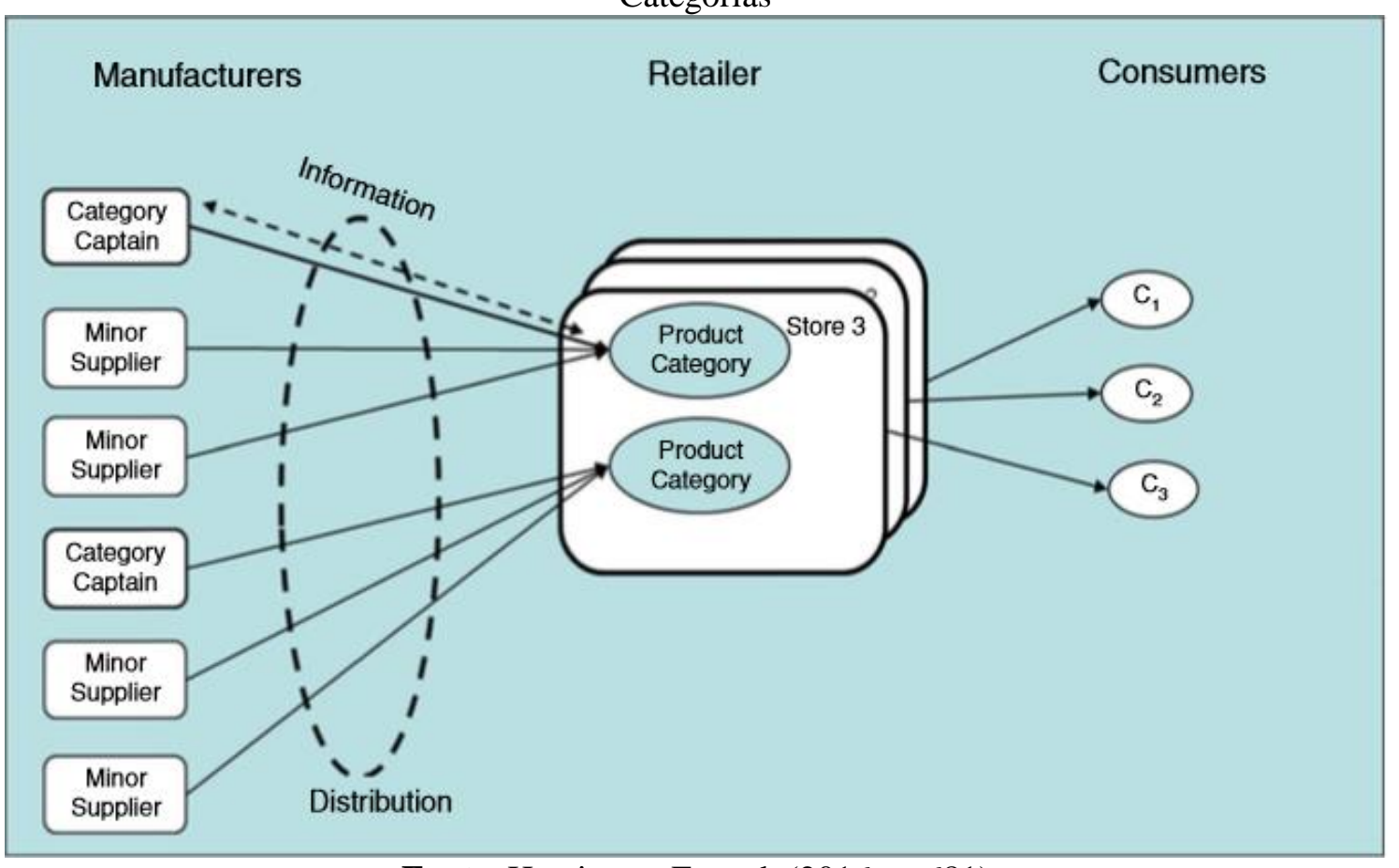

Fonte. Hamister e Fortsch (2016, p. 681)

O processo de Gerenciamento de Categorias é frequentemente implantado pelo chamado Capitão da Categoria (Category Captain - CC), pois normalmente este é o que possui maiores recursos, tanto financeiros quanto técnicos, e por ser ele também o principal beneficiário de um projeto desta magnitude (LINDBLOM; OLKKONEN, 2008). Ainda assim, um projeto de GC pode ser capitaneado pelo próprio varejista, mas estudos demonstram que quando o gestor do processo escolhido (Capitão) é a indústria com maior market share, o potencial de ganho para o varejista e para as outras indústrias (menores) é maior. (KURTULUS et al., 2014).

Conforme o Category Management Report (1995) indica, cada um destes agentes tem benefícios distintos ao longo do processo de GC. A indústria se beneficia, 
principalmente se for o capitão da categoria, por meio do retorno financeiro com o aumento das vendas e de retornos não-financeiros, como a ampliação do conhecimento a respeito do lojista e do comportamento de compra dos shoppers, o que possibilita incrementos no produto e na maneira de se comunicar com os consumidores.

Para o varejista, os benefícios financeiros são o aumento das vendas e da rentabilidade da categoria e os não-financeiros incluem diversos aspectos, como o melhor relacionamento e comunicação com a indústria, o acesso a uma ferramenta de planejamento (GC) que dificilmente seria acessível, dado os altos custos de implantação. Outro aspecto é o melhor entendimento do comportamento do seu consumidor.

Do ponto de vista do shopper, o principal benefício é encontrar na loja um mix de produtos que atenda às suas necessidades, no lugar certo, de maneira organizada. Logo, após a implantação do projeto de GC, a experiência de compra do shopper tende a ser mais satisfatória. Para que estes benefícios sejam percebidos pelo shopper, as práticas de alocação do espaço de prateleira (ponto natural e pontos extras) e de comunicação da categoria são indispensáveis.

\section{Alocação de Espaço}

A atividade de definir o espaço de prateleira de cada categoria até o nível de produto, vem se tornando cada vez mais complicada para os varejistas, tendo em vista a infinidade de lançamentos que as indústrias promovem com o objetivo de garantir seu market share (HÜBNER; KUHN, 2012) versus a o espaço físico disponível para dispor essa infinidade de itens. Segundo estudo de Shaal e Hübner (2018), a demanda de um produto varia dentro da loja, conforme é dada ênfase a sua exposição, isso é chamado de space-elastic demand. Quando é alterado o layout da exposição dentro da loja, dando mais ênfase a um produto específico em detrimento de outro (como o espaço da loja é limitado, o trade off é imperativo), podem ocorrer perdas nas vendas de outros produtos, isso é chamado cross-space elasticity. Seguindo essas premissas, é importante definir critérios ao fazer modificações no layout, de maneira que se maximize a rentabilidade.

Definir o espaço em loja de uma categoria, envolve intervir na quantidade total de espaço alocada para dada categoria e consequentemente a quantidade de frentes de cada unidade de produto na prateleira. A maioria dos estudos envolvendo alocação de espaço focam em como alocar os produtos - por atributo ou benefício, porém deixam de analisar como dispor fisicamente os produtos nas prateleiras (PIZZI; SCARPI, 2016).

Enquanto muitos autores defendem um sortimento amplo e profundo, outros defendem, por meio de experimentos, que às vezes, otimizar o sortimento (reduzir), melhora a performance de algumas categorias, principalmente as de menor giro (PIZZI; SCARPI, 2016). Entretanto, uma alternativa para otimizar o mix sem perder vendas é fazer a escolha dos itens por atributo ou benefício, analisando o grau de substituição e complementariedade de cada um (PARENTE; BARKI, 2014; BOATWRIGHT; NUNES, 2001).

Outro desafio que o varejista se depara, após definir o espaço disponível para cada categoria, é como distribuir os produtos de maneira que maximize a rentabilidade. Segundo Chandon et al. (2009), após um experimento para avaliar se as atividades de marketing praticadas dentro da loja funcionam para a categoria de sabonetes e analgésicos, foi observado que os resultados não são unânimes quando dizem respeito a escolha das marcas, a escolha varia positivamente para usuários regulares, porém para marcas com baixo market share e para jovens com alto nível de escolaridade, o trade off 
entre marca e preço continua predominante. Ainda assim, existe um efeito positivo na atenção e valorização à marca em todos os cenários.

Ainda no mesmo estudo de Chandon et al. (2009), o posicionamento vertical teve graus que variaram em função da localização, quando mais ao topo da prateleira, maior atenção e valorização, enquanto as marcas que ficaram no meio, apenas receberam mais atenção, sem valorização. Para surpresa, tendo em vista que assumimos que a preferência por determinada marca, segue a maneira como praticamos leitura, da esquerda para a direita, o fato das marcas estarem posicionadas a direita ou a esquerda da prateleira, não tiveram influência na atenção, valorização e consequentemente na escolha das marcas.

\section{Exemplos de colaboração indústria e varejo em projetos de GC}

Um estudo feito por Gooner, Morgan e Perreault (2011) com grandes redes varejistas dos EUA, traz a luz um modelo de avaliação de um processo de GC abordando diretamente o papel do Capitão da Categoria no processo. Os resultados deste trabalho indicam que delegar a gestão completa de uma categoria a uma indústria, especialmente se essa indústria for a líder da categoria, incluindo a gestão das marcas das indústrias rivais, aumenta os resultados do processo de GC para ambos, mesmo quando comparado a gestão de categorias executadas pelo próprio varejista. Outro fator importante é que não foi observado aumento de oportunismo ou problema entre os fornecedores (um dos medos apontados pelos varejistas ao designar um capitão para liderar a categoria é o risco dele se aproveitar do acesso às informações para manipular os dados em favor próprio e detrimento dos demais). Porém, ainda que os resultados demonstrem que quanto mais intensa for a colaboração entre os agentes, a delegação da categoria à indústria ainda é um tabu entre grandes redes de varejo.

Temos um estudo brasileiro, executado por Arkader e Ferreira (2004), com três diferentes tipos de autosserviço: grande, médio e uma loja de conveniência (com lojas próprias e franquias). Apesar de possuírem tamanho e estratégias diferentes, todos tinham em comum o fato de serem redes. O principal resultado do estudo foi que o grande varejista tinha conseguido implantar com sucesso seu processo de GC, porém não delegou o processo ao fabricante, pelo fato de possuir um bom sistema de informações (o que vai na contramão do conceito de ECR e de GC, que são baseados na colaboração). A rede de médio varejo e a de pequenas lojas de conveniência é a que menos dispunha de um sistema de informações que possibilitasse a ela conduzir o processo de GC, portanto depende mais da estrutura da indústria para auxiliar a gerenciar. O estudo também aponta que a grande dificuldade para se estabelecer um processo de GC colaborativo entre indústria e varejo é o baixo nível de confiança entre que ainda prevalece nesta relação, onde as negociações são baseadas no curto prazo, beneficiando preço e volume ou invés de cooperação e confiança.

Ainda são raros os estudos envolvendo o pequeno varejo de vizinhança. Guissoni, Consoli e Rodrigues (2013) conduziram um experimento onde um grande player da categoria de refrigerantes - líder no segmento - executa um projeto de GC em pequenos varejos de vizinhança e investiga os resultados do ponto de vista da indústria. O projeto foi um sucesso e provou que investir em um processo de GC para o pequeno varejo vale a pena. Esse estudo foi um marco no que diz respeito a implantação de um processo de GC em um varejo composto por players pequenos e totalmente fragmentados. Um ponto que favoreceu a aceitação destes varejistas a aceitarem o projeto foi a dependência que eles têm desta indústria nas receitas das suas lojas e 
também a sua incapacidade de executar um projeto desta magnitude pela insuficiência de dados e conhecimento técnico.

\section{Cross-category management}

"Se o objetivo principal do Gerenciamento de Categorias é maximizar a lucratividade das marcas de uma categoria de produtos, o objetivo da gestão de crosscategory é otimizar a lucratividade entre categorias." (BEZAWADA et. al., 2009, tradução nossa). Trabalhar o conceito de gerenciamento de cross-category, ou seja, de categorias que são complementares durante a jornada de compras do consumidor é estratégico, ainda mais quando a categoria chave da análise é uma categoria classificada como destino e atração.

Estudos de Musalem e Aburto (2018) demonstram a importância de se trabalhar o conceito de cross-category de maneira tática dentro da loja, utilizando uma dada categoria como gatilho para a compra de outras. Isso implica em analisar a correlação entre as categorias e amplia o conceito tradicional de gerenciamento de categorias.

Isso não significa trabalhar apenas o conceito de cross-category envolvendo categorias correlatas, ou seja, que tenham alta probabilidade de compra em conjunto, próximas uma da outra. As categorias devem ser analisadas sob uma ótica mais ampla, considerando aproximar categorias que a princípio não tem correlação nenhuma e distanciar categorias com alta correlação, aumentando a circulação dos shoppers dentro da loja, o que pode implicar em incrementos no ticket médio, por exemplo. Porém, isso pode implicar em insatisfação do consumidor a respeito da qualidade do serviço prestado durante a sua jornada dentro da loja (HONG; MISRA; VILCASSIM, 2016).

Decisões envolvendo alocação de espaço e sortimento devem ser tomadas de maneira a estimular todas as categorias de produtos na loja, especialmente as que se referem a compram não-planejadas e feitas por impulso (FLAMAND et. al., 2018).

\section{PROCEDIMENTOS METODOLÓGICOS}

\section{A importância da categoria de papel}

A categoria de papel é considerada como Categoria de Destino e é considerada por muitos varejistas do setor, quando questionados sobre a sua relevância, como sendo o mesmo que "o pão francês da padaria para o padeiro", ou seja, tem grande importância nas receitas totais.

Segundo as informações obtidas com as entrevistas, as vendas da categoria de papel em uma papelaria ocorrem em dois canais, uma pelas vendas realizadas para clientes corporativos (B2B), denominado neste estudo como tele-vendas, que representam aproximadamente $70 \%$ das vendas da categoria e até $20 \%$ do faturamento total das lojas do experimento. O outro canal é denominado como balcão e representa as vendas feitas no balcão da loja (B2C), que respondem por aproximadamente $30 \%$ das vendas da categoria e até $9 \%$ das receitas das lojas do experimento. Este experimento tem apenas impacto no canal B2C.

Outro aspecto que deve ser considerado é a grande sazonalidade que existe nas vendas da categoria de papel no período de volta as aulas, que compreende de Dezembro a Fevereiro todos os anos. Neste período são observados aumentos de mais de $100 \%$ nas vendas de balcão. Apesar do estudo não ser de natureza quantitativa, a implantação do projeto foi retardada o mês de Fevereiro de 2019, a fim de possibilitar aos proprietários das lojas uma melhor avaliação da intervenção (sem o efeito sazonal). 


\section{Metodologia de pesquisa, procedimento e objetivos}

A metodologia de pesquisa aplicada no piloto é o método de pesquisa qualitativo. Essa abordagem busca explorar os conhecimentos obtidos por meio da sua fonte de pesquisa e a partir daí tenta explicar um fenômeno ou as consequências geradas por uma intervenção em determinado ambiente do ponto de vista da percepção do universo investigado. O resultado da aplicação deste método quase sempre é imprevisível. O objetivo da amostra é de produzir informações aprofundadas e ilustrativas: seja ela pequena ou grande, o que importa é que ela seja capaz de produzir novas informações (DESLAURIERS, 1991). O procedimento adotado para essa pesquisa foi o Estudo de Caso.

Para atingir os objetivos do estudo de caso, foram realizadas entrevistas de profundidade (pesquisas exploratórias) com os proprietários (tomadores de decisão) das papelarias, para entender como eles enxergam a categoria de papel dentro da loja, sua importância e representatividade no negócio. Também foram abordados aspectos relativos a opinião destes agentes a respeito da indústria que esta capitaneando o piloto, bem como das suas marcas. Os resultados da análise das entrevistas foram a base para montar a proposta de intervenção na categoria. Também foram feitas pesquisas de reação pós-implantação para avaliar se houve mudança na percepção dos proprietários em relação às intervenções que foram executadas no modelo de exposição da categoria de papel na loja.

O passo a passo para a realização do piloto e da pós intervenção pode ser observado nos Quadros 1 e 2.

Quadro 1. Cronograma pré-intervenção

\begin{tabular}{|c|c|c|c|c|c|c|c|c|c|}
\hline Pré-intervenção & mar/18 & $\mathrm{abr} / 18$ & $\mathrm{mai} / 18$ & jun/18 & jul/18 & ago/18 & set/18 & out/18 & nov/18 \\
\hline \multicolumn{10}{|l|}{ Escolha das regiões } \\
\hline \multicolumn{10}{|l|}{ Escolha das lojas } \\
\hline \multicolumn{10}{|l|}{ Entrega do convite para os proprietários } \\
\hline \multicolumn{10}{|l|}{ Coleta de fotos pré-implantação } \\
\hline \multicolumn{10}{|l|}{ Entrevistas de profundidade com os proprietários } \\
\hline \multicolumn{10}{|l|}{ Elaboração das propostas de intervenção } \\
\hline Confeccção e validação dos materiais & & & & & & & & & \\
\hline
\end{tabular}

Fonte. Elaborado pelo autor (2019)

Quadro 2. Cronograma pós-intervenção

\begin{tabular}{|r|c|c|c|c|c|c|}
\hline Pós-intervenção & fev/19 & mar/19 & abr/19 & $\mathrm{mai} / 19$ & jun/19 & jul/19 \\
\hline Implantação das intervenções & & & & & & \\
\hline Captação dos registros pós-implantação & & & & & & \\
\hline Período de monitoramento do piloto & & & & & & \\
\hline Entrevistas de reação com os proprietários (pós) & & & & & & \\
\hline
\end{tabular}

Fonte. Elaborado pelo autor (2019)

\section{Processo de escolha e convite das lojas para participarem do projeto}

As lojas foram escolhidas para participar do piloto segundo duas premissas: relacionamento comercial e participação no programa de fidelidade. Primeiro foram definidas as regiões onde o piloto seria implementado. A primeira região foi São Paulo (região metropolitana) por ser o maior mercado da categoria e pela facilidade de acompanhamento da execução. A segunda região foi o interior de São Paulo, por ser um mercado extremamente competitivo. A terceira região foi Salvador-BA por ser o mercado com market share concentrado no segmento de papelarias. Foram escolhidas 
seis lojas: duas em Salvador-BA, uma em Sorocaba-SP, uma em São Caetano do SulSP e duas em São Paulo-SP. As lojas possuem tamanhos distintos, duas são consideradas de grande porte, três de médio porte e duas de pequeno porte. Todas funcionam no formato de autosserviço e possuem atendentes espalhados pela loja a fim de auxiliar o shopper na sua jornada de compras.

\section{Entrevistas com os proprietários das lojas}

Em Maio de 2018, juntamente com a captura e registro das execuções da categoria de papel em cada uma das lojas, foram feitas entrevistas exploratórias com os proprietários das papelarias para identificar as percepções relacionadas a categoria de papel e sua relevância no negócio de cada uma, quais as principais marcas e fabricantes, a atuação dos fornecedores, posicionamento de preços, racional de exposição e percepção dos shoppers. Em Julho de 2019, foram realizadas, via telefone, as entrevistas exploratórias de reação para avaliar a percepção dos varejistas a respeito do experimento, como: alterações da nova localização e da nova comunicação e exposição da categoria. Também foram questionados a respeito de alterações no comportamento do shopper e sobre variações nas vendas.

\section{Proposta e método de aplicação das intervenções}

Adotando a premissa coletada nas entrevistas exploratórias (antes das intervenções), de que o papel da categoria é Destino, o objetivo foi propor um planograma de exposição padrão para toda a categoria de papel. A partir da observação das lojas e das entrevistas com os lojistas, foi identificado que a categoria não tem um padrão de exposição: algumas lojas deixam o produto logo na entrada da loja ou no check out, o que faz com que o shopper circule pouco pela loja quando vem comprar papel e outras já perceberam que é melhor que o papel fique no fundo da loja, aumentando a circulação do shopper pelos corredores; utilizam pontas de gôndola como ponto natural para a categoria; expõe o papel de forma horizontalizada, geralmente na última prateleira; a quantidade de MPDVs é praticamente inexistente; a maioria das lojas monta pilhas com as resmas, muitas vezes utilizando a própria caixa como base para fazer a exposição, sendo que muitas vezes esta era a única forma de expor o produto em algumas lojas.

Outro aspecto importante é que o sortimento de marcas, com diferentes posicionamentos de preços, varia muito de loja para loja (50\% das lojas do experimento trabalham com 3 a 4 fabricantes/fornecedores). A justificativa para tamanha profundidade da categoria encontrada nas lojas em parte é explicada pela demanda por papéis de primeira e segunda linha, ou seja, um papel reconhecido pela qualidade e outro com apelo a preço. Ainda assim, foram observadas diversas marcas concorrendo no mesmo posicionamento, muitas vezes com preços iguais na mesma loja.

Além das entrevistas, foram coletadas as seguintes informações préexperimento: registros fotográficos da categoria de papel, captação de preço, sortimento, informações sobre o layout (planograma com quantidade de módulos e localização). A partir destes levantamentos, foi elaborada uma proposta de exposição para a categoria de papel com três intervenções: criação de um ponto-natural, comunicação e ativação de pontos-extras. As intervenções foram realizadas durante o mês de Fevereiro de 2019. A seguir o detalhamento das intervenções que foram realizadas: 
i. Criação do ponto-natural da categoria de papel, incluindo os três principais grupos: papel sulfite (A4 $75 \mathrm{~g}$ branco), papéis coloridos e outros formatos (coloridos, 90g, A3, carta, ofício, reciclado) e papéis especiais (fotográficos, papel-cartão, etc.);

ii. Comunicação de toda a categoria de papéis, utilizando um padrão de comunicação pré-definido com materiais de ativação de curta, média e longa distância dentro da papelaria;

iii. Ativação de pontos-extras explorando os conceitos de cross-selling e crosscategory, como materiais de escritório, escolares, alguns suprimentos de informática, como cartuchos de tinta e tonners para impressoras (critério a ser definido em cada papelaria de acordo com a necessidade de cada uma).

Para as intervenções, foram considerados o tamanho de cada loja e o número de módulos, sendo cada módulo uma unidade de gôndola onde estariam presentes todos os produtos da categoria. Os módulos foram criados para serem adaptados a cada tipo de loja e foram fabricados com quatro modelos de testeira: uma indicando apenas "Papéis", para lojas menores onde foi implantado apenas um módulo e seria o lugar para colocar todos os tipos de papéis com foco no sulfite A4, coloridos e outros formatos. Os outros três módulos tem testeiras que são sequenciais para uma exposição completa de toda sessão de papéis: uma indicando "Papel Sulfite A4 - Para Imprimir e Escrever" para lojas com capacidade para mais de um módulo; uma indicando "Papéis Coloridos/Outros Tipos - Para Usos Diversos" que foi colocada em duas lojas e; uma indicando "Papéis Especiais", que foi colocado em apenas uma loja que recebeu os três módulos. Três lojas receberam um módulo, duas lojas receberam dois módulos e uma loja recebeu três módulos.

Quadro 3. Perfil das lojas por tamanho e quantidade de módulos implantados

\begin{tabular}{|c|c|c|}
\hline Lojas & Tamanho & Qtde módulos implantados \\
\hline Loja 1 & Grande & 3,00 \\
\hline Loja 2 & Média & 1,00 \\
\hline Loja 3 & Média & 1,00 \\
\hline Loja 4 & Grande & 2,00 \\
\hline Loja 5 & Pequena & 1,00 \\
\hline Loja 6 & Média & 2,00 \\
\hline & TOTAL & 10,00 \\
\hline
\end{tabular}

Fonte. Elaborado pelo autor (2019)

\section{Análise documental}

O primeiro passo foi se certificar qual o papel que a categoria exercia na loja. Como em todos os casos ele se apresentou como categoria destino, a proposta de intervenção buscou posicionar o papel na loja de maneira que o shopper circulasse ao máximo pela loja, amentando a possibilidade de comprar outros itens. A partir das observações na loja, foi desenhado o layout atual e um layout com a proposta para a nova localização da categoria.

As Figuras 4 e 5 representam o layout da Loja 5, antes e depois das intervenções. Neste caso pode-se observar que antes das intervenções o papel estava 
posicionado na entrada da loja, junto ao checkout. Desta forma, o cliente entrava na loja, ia direto ao caixa, pegava o papel sulfite, pagava e saia da loja. A partir dos relatos do proprietário, que gostaria que o shopper circulasse mais pela loja, foi feita uma proposta de layout posicionando o papel no fundo da loja.

Figura 4. Exemplo de layout antes das intervenções (Loja 5)

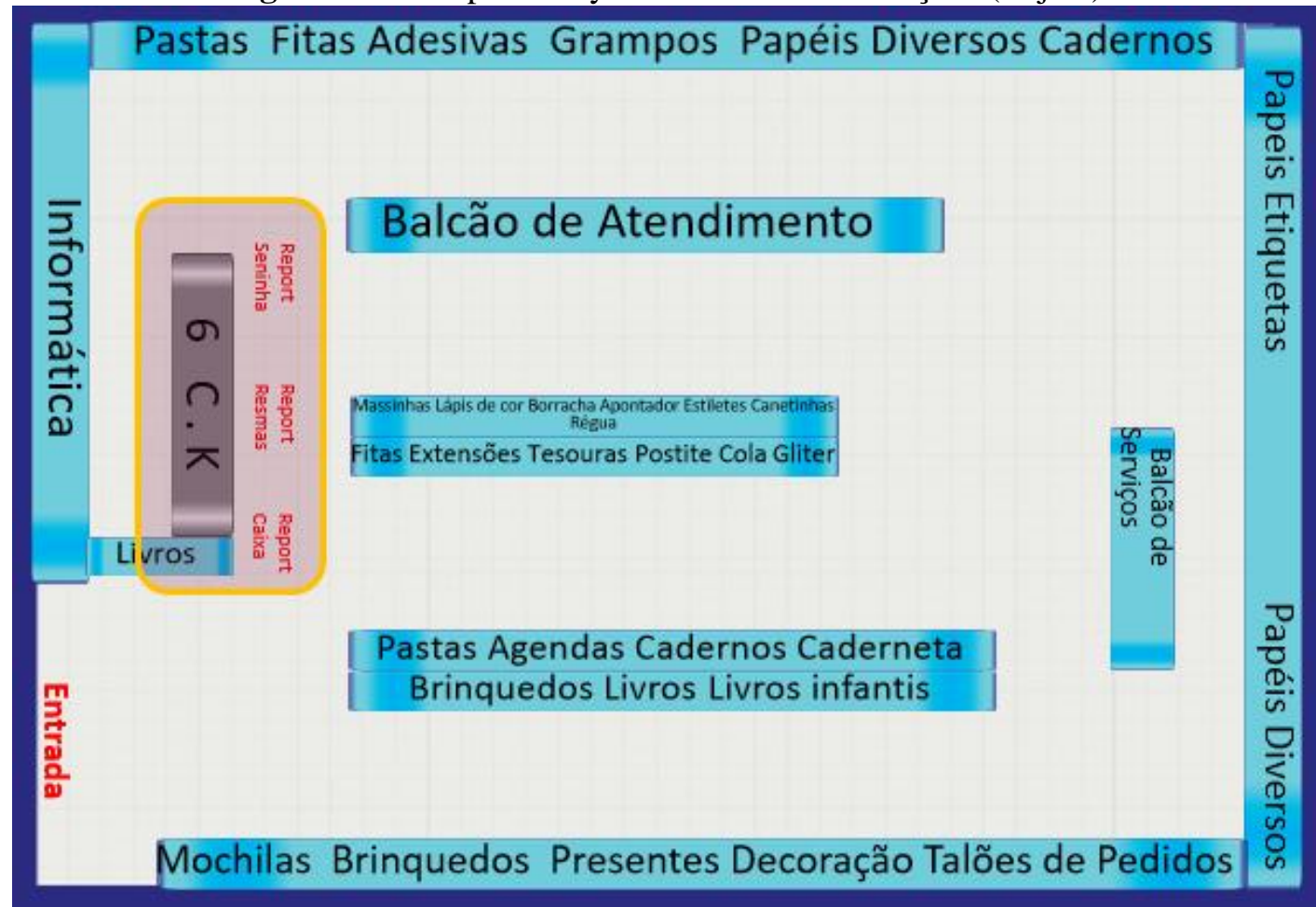

Fonte. Elaborado pelo autor (2018)

Figura 5. Exemplo de layout pós- intervenções (Loja 5)

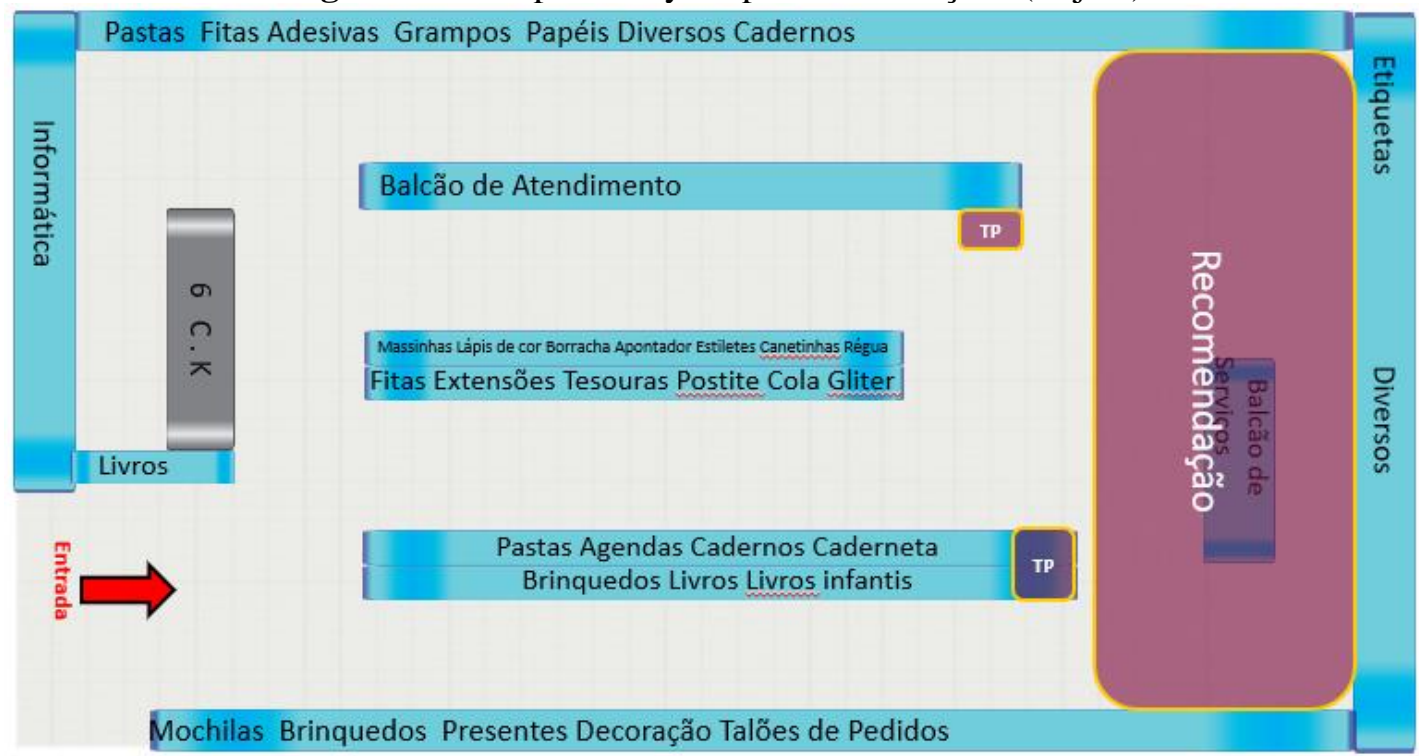

Fonte. Elaborado pelo autor (2018) 
A Figura 6 mostra as fotos antes e depois da execução seguindo o layout acima.

Figura 6. Ponta de gôndola antes e após intervenções (Loja 5)

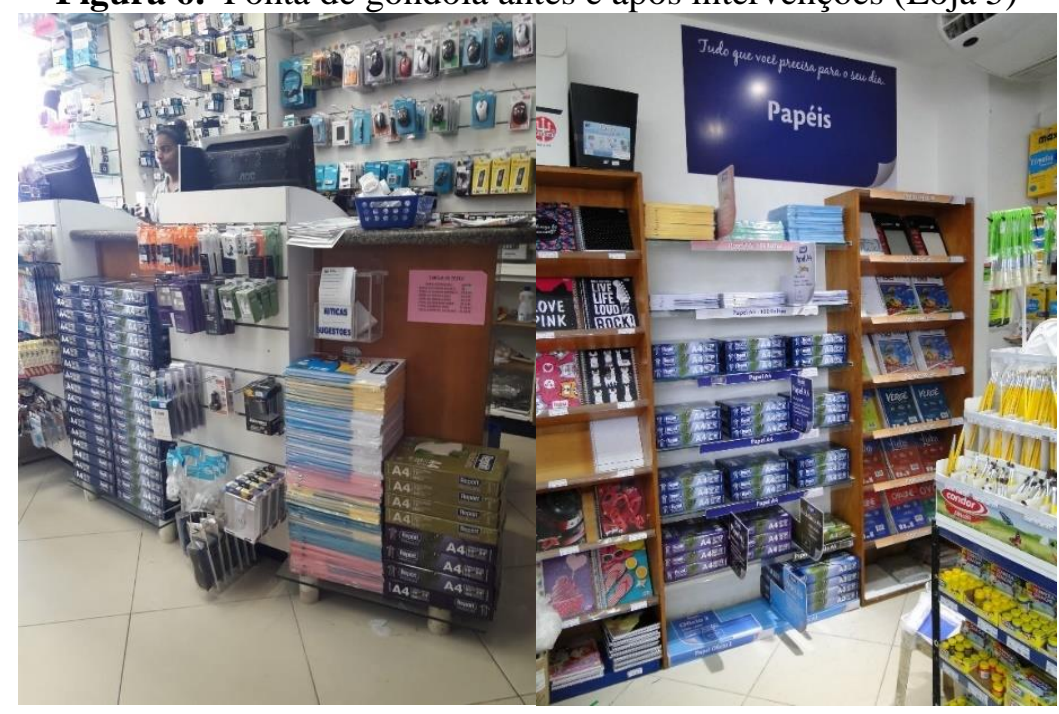

Fonte. Elaborado pelo autor (2018)

\section{RESULTADOS}

Análise das entrevistas exploratórias (pré-experimento)

a. Importância da categoria de papel: Todos os entrevistados reconhecem o papel como Categoria de Destino. Ele representa até 9\% das vendas de balcão (pessoa física) e até $30 \%$ quando considerado televendas (pessoa jurídica). Também foi elencado algumas categorias correlatas, como cartuchos de tinta para impressora, caneta e lápis, grampeador, pastas, envelopes. Além disso, foi solicitado que citassem as principais reclamações dos shoppers sobre a categoria: variação de preços, seguido pela qualidade, mudança da localização da categoria dentro da loja, não encontrar a marca que está habituado a comprar, embalagens parecidas de produtos diferentes (A4, Carta, Ofício). Também identificaram a sazonalidade de vendas da categoria que é o período de volta às aulas (dezembro a fevereiro).

b. Precificação da categoria: Existem produtos com posicionamento de preços muito similar em algumas regiões e a maioria dos entrevistados não consegue diferenciar o motivo desta diferenciação. Alguns até enxergam a Marca 1 como superior, mas entendem que a qualidade da Marca 2 já é suficiente para o nível de exigência dos clientes que tem mais apelo por qualidade. Alguns entrevistados afirmaram que veem espaço para embalagens menores de produtos coloridos (por exemplo uma embalagem com 100 folhas e cinco cores, ou invés do padrão de 500 folhas encontrado hoje).

c. Processos: Os entrevistados foram questionados sobre como eram atualizados sobre as novidades e tendências do mercado e afirmaram que hoje não tem nenhum canal de comunicação oficial onde possam se atualizar sobre novidades e tendências. Ainda no quesito processos todos afirmaram que tem controle detalhado das vendas (separando balcão e televendas) e estariam dispostos a compartilhar essas informações com a Indústria. Este último tópico foi o ponto mais delicado enfrentado pois mesmo após a confirmação de que iriam compartilhar os dados e da assinatura dos termos de 
compromisso, alguns deles relutaram em fornecer as informações ou forneceram de maneira incompleta. Esse ponto corrobora com o que foi relatado na literatura sobre a desconfiança que permeia a relação entre varejistas e indústria, como no estudo de Gooner, Morgan e Perreault (2011) sobre GC e as relações entre os varejistas e indústria.

d. Racional de exposição (antes/atual): Não existe um padrão de exposição, sendo que cada lojista define o racional de exposição da sua loja. O que se observou em algumas lojas é que existem alguns poucos materiais de ponto de venda (MPDV) fornecidos pelos dois principais fornecedores de papel, todos materiais leves, como displays de chão e balcão. Ainda assim, nenhuma marca foi mencionada como destaque ou como referência em exposição. Outro aspecto importante que os lojistas foram questionados foi com que frequência alteram o layout da categoria, onde $50 \%$ respondeu que não altera durante o ano e os outros 50\% alteram em função de alguma sazonalidade, como o período de Volta as Aulas. Quanto a localização na loja, $70 \%$ dos lojistas tem ao menos 2 pontos naturais de exposição, sendo um ponto localizado em ponta de gôndola e outro com as caixas dispostas no chão em outro local da loja. Um ponto que chamou a atenção é que alguns lojistas expõe o papel no fundo da loja e na entrada da loja ou perto dos caixas. Essa última forma de expor a categoria (na entrada da loja ou perto dos caixas) contradiz a literatura e o entendimento de que o papel, por ser um considerado Categoria de Destino, deve sempre estar localizado ao fundo da loja, possibilitando que as pessoas circulem pelos corredores, aumentando a probabilidade de comprar mais itens, enquanto localizam o papel.

Ainda neste item, foi solicitado que os lojistas elencassem quais os principais obstáculos encontrados para expor a categoria de papel: espaço físico limitado (área de vendas e armazenagem); item pesado e de alto giro; e exposição dos itens complementares da categoria (Carta, Ofício, coloridos, 100 folhas, reciclados). A exposição dos itens complementares foi um ponto de preocupação dos entrevistados, pois muitos ainda tem dificuldade e receio de expor os itens, principalmente papéis de outros formatos (Carta, Ofício 2 e 9) devido a incidência de erro por parte do consumidor na hora de escolher o produto na gôndola, muitos orientam os caixas a questionar se o consumidor tem certeza que escolheu o formato correto. Também ocorrem erros por parte do shopper devido ao fato das embalagens do mesmo produto de marcas e fabricantes diferentes serem muito semelhantes.

e. MPDV: Os proprietários foram questionados a respeito de materiais que hoje tem a sua disposição na papelaria fornecido pela indústria e sua percepção a respeito das melhores práticas de outras indústrias e fornecedores. A percepção é a de que os materiais existentes não atendem as suas necessidades. O Quadro 4 apresenta a visão dos lojistas quanto à eficiência e a não eficiência.

Quadro 4. Características dos MPDVs na visão dos lojistas

\begin{tabular}{|lr|l|}
\hline Eficientes & Não-eficientes \\
\hline $\begin{array}{l}\text { Bases de pilha resistentes (água e } \\
\text { movimentação) }\end{array}$ & Materiais leves frágeis, displays de papelão \\
\hline Displays práticos e resistentes & Adesivos (dão a impressão de ambiente polúido) \\
\hline $\begin{array}{l}\text { Expositores menores que caibam na } \\
\text { prateleira }\end{array}$ & $\begin{array}{l}\text { Expositores com baixa capacidade (exigem muita } \\
\text { reposição) }\end{array}$ \\
\hline $\begin{array}{l}\text { Cubo de papelão, mobiles, faixas de } \\
\text { gôndola, stooper }\end{array}$ & Expositores grandes para lojas pequenas \\
\hline
\end{tabular}


Revestimento de colunas (plotagem)

Fonte. Elaborado pelo autor (2019)

f. Percepções a respeito do shopper e da jornada de compra dentro do PDV: Nesta questão os entrevistados foram incentivados a fornecer suas impressões a respeito do shopper da categoria de papel. Quanto a frequência de compra, o perfil do shopper pode ser divido em recorrente e novo. O novo shopper que entra no PDV para comprar sulfite e não encontra o produto, sempre pede ajuda a um atendente. Nesse caso, se o shopper não pedir por uma marca específica, o poder de decisão da escolha da marca fica com o atendente. Quanto ao posicionamento, também pode-se dividir em dois, um altamente sensível a custo (preço) e outro sensível a qualidade. Eles migram de marca dentro do seu perfil de posicionamento, mas raramente mudam de posicionamento. Os mais suscetíveis a preços, geralmente são os shoppers do segmento corporativo (B2B).

Quanto ao volume comprado, os shoppers do segmento corporativo compram acima de 10 resmas e os shoppers do balcão de loja, caracterizados pelos usuários domésticos, que compram de 1 a 2 resmas. Ainda assim, a maioria dos clientes de papel sulfite é fiel a loja, os que são fiéis a alguma marca específica, geralmente são os shoppers que valorizam mais a qualidade na hora da decisão.

\section{Análise das entrevistas exploratórias (pós-experimento)}

Após a implantação das intervenções, os proprietários das lojas foram entrevistados para analisar diversos pontos relacionados a execução do experimento. Os questionários foram aplicados em Julho de 2019 via contato telefônico.

a. Manutenção do layout: Das lojas que participaram do experimento, apenas uma das lojas alterou a localização proposta na intervenção, as outras mantiveram a proposta. A organização e o destaque que a nova exposição proporcionou para a categoria foram os mais citados como principais motivadores para manutenção do novo layout de exposição. Nas lojas que sofreram alteração do ponto natural da categoria, os entrevistados foram questionados quanto a adaptação do shopper à nova localização e afirmaram que alguns clientes recorrentes reclamaram um pouco da mudança, mas que se adaptaram. Também comentaram que estavam satisfeitos com a nova localização, pois agora o cliente circula mais pela loja, aumentando a probabilidade de vender outros produtos.

b. Mudanças no comportamento do shopper e dos atendentes: Todos os entrevistados relataram que os atendentes da loja se adaptaram facilmente ao novo modelo de exposição. Relataram também que o novo layout e comunicação facilitaram a reposição dos produtos e que os próprios atendentes passaram a entender melhor a utilidade de cada papel na categoria. Esse era um ponto de melhoria citado nas entrevistas exploratórias pré-experimento.

A maioria das lojas afirmaram que perceberam alterações no comportamento do shopper, afirmando que com a nova comunicação da categoria, eles não pedem mais tanta ajuda para o time de atendimento, reduzindo a incidência de erros na hora da compra (um dos pontos de melhoria levantado nas entrevistas exploratórias préexperimento).

Todas os entrevistados citaram uma melhora substancial da organização da categoria com o novo layout. Um dos pontos levantados por meio de observações antes do experimento, era o de que a categoria ficava dispersa pela loja, muitas vezes tendo a como o seu ponto natural algumas pilhas de caixa com as resmas em cima. Com o 
projeto, a categoria está organizada, com destaque especial para os itens que compõe os papéis coloridos e outros tipos (carta, ofício, A3, 90grs), que geralmente recebiam menos atenção quanto a exposição nas lojas, quase sempre posicionados em locais com pouca visibilidade.

$\checkmark \quad$ Principais benefícios do projeto: foram listados os seguintes benefícios: maior exposição dos produtos que compõe a categoria; melhora na ambientação da loja; facilidade de reposição e atendimento; os clientes estão "errando" menos e solicitando menos ajuda dos atendentes;

c. Percepção sobre a variação nas vendas da categoria: Com exceção de uma das lojas, todos os lojistas afirmaram que a notaram aumento nas vendas de alguns itens da categoria, principalmente de papéis coloridos e outros tipos (carta, ofício, A3, 90grs). Os entrevistados afirmaram que o papel sulfite A4 75 grs de 500 folhas, considerado como o principal produto da categoria, tem um apelo muito forte a variável preço, por esse motivo não sofreu impacto com o projeto.

Por outro lado, os papéis coloridos e outros tipos tiveram um desempenho melhor com a implantação do experimento. Com a nova exposição, esses papéis receberam destaque, sendo esse o principal motivo apontado pelos entrevistados para justificar a variação positiva de vendas.

d. Avaliação dos principais pontos do projeto. Os dados estão sistematizados no Quadro 5.

Quadro 5. Escala de Likert - pós-intervenções

\begin{tabular}{|l|c|c|c|c|c|c|}
\hline & $\begin{array}{c}\text { Loja } \\
\mathbf{1}\end{array}$ & $\begin{array}{c}\text { Loja } \\
\mathbf{2}\end{array}$ & $\begin{array}{c}\text { Loja } \\
\mathbf{3}\end{array}$ & $\begin{array}{c}\text { Loja } \\
\mathbf{4}\end{array}$ & $\begin{array}{c}\text { Loja } \\
\mathbf{5}\end{array}$ & $\begin{array}{c}\text { Loja } \\
\mathbf{6}\end{array}$ \\
\hline $\begin{array}{l}\text { Visualmente que nota você daria para a nova } \\
\text { localização da categoria na loja em relação a } \\
\text { exposição anterior? (Pouco atraente 1/ Muito } \\
\text { Atraente 5) }\end{array}$ & 4 & 5 & 5 & 5 & 5 & 5 \\
\hline $\begin{array}{l}\text { Que nota você daria para os materiais de } \\
\text { merchandising utilizados para sinalizar a } \\
\text { categoria? (Pouco eficiente 1/ Muito eficiente } \\
\text { 5) }\end{array}$ & 3 & 2 & 4 & 5 & 5 & 5 \\
\hline $\begin{array}{l}\text { Você acha que o projeto contribuiu para os } \\
\text { resultados da sua loja? (Não contribuiu em nada } \\
\text { 1 / Contribuiu muito 5) }\end{array}$ & 4 & - & 5 & 3 & 5 & 4 \\
\hline
\end{tabular}

Fonte. Elaborado pelo autor (2019)

O Quadro 5 busca avaliar, utilizando a Escala Likert, qual a nota que cada varejista daria para três pontos-chave pós-implantação do experimento: localização, MPDVs e se o projeto contribui para os resultados da loja. Do ponto de vista de localização, com exceção de um participante, todos os outros avaliaram com nota máxima. Já quanto aos MPDVs utilizados, existe uma oportunidade de melhoria. Do ponto de vista de resultados, não foi unânime por parte dos varejistas que o projeto contribuiu para os resultados da loja, apesar de todos os benefícios e aspectos qualitativos citados por eles durante as entrevistas. 
Análise das intervenções. Os dados estão sistematizados no Quadro 6.

Quadro 6. Análise das Intervenções - Antes e depois

\begin{tabular}{|c|c|c|c|c|c|c|c|c|}
\hline \multirow[b]{2}{*}{ PDVs } & \multirow[b]{2}{*}{$\begin{array}{l}\text { Tamanh } \\
\text { o da loja }\end{array}$} & \multicolumn{2}{|c|}{$\begin{array}{l}\text { Ponto natural } \\
\text { (PN) }\end{array}$} & \multicolumn{2}{|c|}{$\begin{array}{l}\text { Ponta de } \\
\text { gôndola (PG) }\end{array}$} & \multicolumn{3}{|c|}{ Variação (antes e depois) } \\
\hline & & Antes & Depois & Antes & Depois & $\begin{array}{l}\text { Ganhos } \\
\text { de frentes } \\
\text { de } \\
\text { prateleira } \\
\text { (pós) }\end{array}$ & $\begin{array}{l}\text { Ativação de } \\
\text { Ponto extra } \\
\text { (pós) }\end{array}$ & $\begin{array}{l}\text { Qtde } \\
\text { módulos } \\
\text { implantad } \\
\text { os }\end{array}$ \\
\hline Loja 1 & Grande & 12,00 & 41,00 & 12,00 & 8,00 & 25,00 & 2,00 & 3,00 \\
\hline Loja 2 & Média & - & 35,00 & 17,00 & 17,00 & 35,00 & 0,00 & 1,00 \\
\hline Loja 3 & Média & 17,00 & 22,00 & - & 12,00 & 17,00 & 1,00 & 1,00 \\
\hline Loja 4 & Grande & - & 45,00 & - & 6,00 & 51,00 & 1,00 & 2,00 \\
\hline Loja 5 & Pequena & 4,00 & 19,00 & - & - & 15,00 & 0,00 & 1,00 \\
\hline Loja 6 & Média & 15,00 & 47,00 & 4,00 & 8,00 & 36,00 & 0,00 & 2,00 \\
\hline TOTAI & & 48,00 & 209,00 & 33,00 & 51,00 & 179,00 & 4,00 & 10,00 \\
\hline
\end{tabular}

Fonte. Elaborado pelo autor (2019). Nota. Expresso em unidades expostas, frentes de gôndola (1 resma $=1$ unidade de frente de exposição)

No Quadro 6 é possível observar os ganhos de espaço de gôndola com o novo layout de exposição. Foram instalados dez módulos de exposição, que equivalem a uma unidade de gôndola de $1,5 \mathrm{~m}$, sendo de dois a três nas lojas de grande porte e um nas lojas de pequeno e médio porte. Todas as pilhas de resmas foram eliminadas das lojas sendo substituídas por ponto-extra ou diretamente pelo ponto-natural. Não foram implantados pontos-extras em todas as lojas devido a limitações de espaço físico e layout da loja.

\section{CONSIDERAÇÕES FINAIS}

Após as entrevistas de reação foi possível responder à questão de pesquisa e afirmar que dentro das lojas participantes do experimento, a alteração do modelo de exposição da categoria de papel alterou a opinião dos varejistas que participaram do piloto. Isso pode ser observado com as contribuições que citam os ganhos visuais obtidos por meio do experimento, como a melhoria na ambientação da loja, maior exposição e visibilidade da categoria de papel.

Outro fator crucial, que foi citado nas entrevistas exploratórias antes da implantação, foram as melhorias para efetuar a reposição e o atendimento. Após a 
implantação os lojistas afirmaram que os clientes estão mais independentes (quando chegam na categoria já conseguem escolher os itens, pois toda a explicação esta na prateleira junto a cada tipo de produto). Foram observados também percepções de variações positivas nas vendas de alguns itens da categoria, como papéis coloridos e outros tipos (carta, ofício, A3, 90grs), porém não no produto que é o carro chefe das vendas da categoria - papel sulfite A4 75grs de 500 folhas. Para esse item, alguns dos entrevistados afirmaram que o grande apelo é o preço e que intervenções na exposição não trariam mudanças nas vendas. Porém, essa afirmação só poderia ser confirmada por meio de uma análise quantitativa dos dados de sell out.

\section{Contribuições}

O piloto contribui para o meio acadêmico e organizacional, possibilitando uma análise qualitativa da alteração da percepção de uma amostra de lojas de varejo do segmento de papelarias após a realização de intervenções no modelo de exposição na categoria de papel. Todas as lojas que participaram das entrevistas de reação afirmaram que foram impactadas positivamente com o projeto, umas em maior e outras em menor intensidade.

Os resultados deste experimento podem se transformar em um Book de Execução e treinamento para a força de vendas. Outra oportunidade identificada é trabalhar nos pontos de oportunidade apontados nas entrevistas, principalmente os relacionados a política comercial, que não é compreendido nem pelo varejista e nem pelo shopper da categoria e isso impactou inclusive na percepção dos resultados quantitativos do experimento por parte dos próprios varejistas. Estabelecer uma política comercial com posicionamento claro para cada uma das marcas e para cada um dos canais trabalhados é uma das formas de capitalizar o apoio deste canal de vendas (papelarias) para a indústria.

A temática de inovação e suas implicações no futuro dos negócios, tão presente nas discussões das grandes indústrias, que não é diferente no setor de papel e celulose, não está chegando aos varejistas. Criar um canal de comunicação institucional que faça com que as novidades e estudos que estão sendo feitos pela indústria, também deve ser vista como uma chance de melhorar a forma como os varejistas enxergam e valorizam essa indústria.

\section{Limitações do Estudo e Sugestões para Pesquisas Futuras}

A principal limitação do estudo diz respeito a falta dos dados de sell out completos da categoria de papel para a realização das análises quantitativas. A justificativa dos varejistas para a não entrega dos dados completos dentro do prazo solicitado é a de que eles não trabalham com um sistema de gestão que faça a separação das vendas B2C das vendas B2B e portanto a dificuldade na extração. Para pesquisas futuras envolvendo o segmento de pequeno varejo, é indispensável receber e avaliar os dados antes do início da execução do projeto, ainda mais quando existir um grau de complexidade como o caso da venda da categoria de papel (B2B e B2C).

Como sugestão para pesquisas futuras, pode ser um estudo mais profundo da precificação nos diversos canais de venda, com o objetivo de descobrir qual a melhor estratégia de preços para a categoria para cada canal. Tendo em vista que esse foi um ponto de dor identificado durante as entrevistas. Outra sugestão para o setor de papelarias é fazer um estudo para identificar todas as categorias de uma papelaria, classifica-las de acordo com cada finalidade (destino, conveniência, rotina, sazonal) e 
então propor um modelo genérico de exposição para toda a loja de maneira que seja possível identificar a relevância de cada categoria e qual a melhor maneira de se trabalhar a execução em loja. Como sugestão de pesquisa futura neste mesmo canal e segmento é entender os impactos de iniciativas como essa do ponto de vista shopper, de maneira que seja possível identificar se um programa de GC, de fato torna o ambiente de loja e consequentemente a jornada de compra do shopper mais agradável, atraindo o shopper para a loja física.

Os pontos acima refletem a grande carência que o varejo, em especial este segmento tem por parte das indústrias para fortalecer a gestão dos seus negócios, o que pode vir a se tornar um ciclo virtuoso onde todas as partes ganham, como foi com esse experimento e como já ocorreu em outros casos já identificados pela literatura, como o estudo de Guissoni, Consoli e Rodrigues (2013) sobre um programa de Gestão de Categorias implantado em pequenos autosserviços de vizinhança.

\section{REFERÊNCIAS}

ARKADER, R.; FERREIRA, C. F. Category management initiatives from the retailer perspective: a study in the Brazilian grocery retail industry. Journal of Purchasing and Supply Management, v. 10, n. 1, p. 41-51, 2004.

BEZAWADA, R. et al. Cross-Category Effects of Aisle and Display Placements: A Spatial Modeling Approach and Insights. Journal of Marketing, [s. 1.], v. 73, n. 3, p. 99-117, 2009.

BOATWRIGHT, P.; NUNES, J. C. Reducing Assortment: An Attribute-Based Approach. Journal of Marketing, [s. 1.], v. 65, n. 3, p. 50-63, 2001.

CATEGORY MANAGEMENT REPORT. The Joint Industry Project on Efficient Consumer Response. 1995.

CHANDON, P. et al. Does In-Store Marketing Work? Effects of the Number and Position of Shelf Facings on Brand Attention and Evaluation at the Point of Purchase. Journal of Marketing, [s. 1.], v. 73, n. 6, p. 1-17, 2009.

CORSTEN, D.; KUMAR, N. Do Suppliers Benefit from Collaborative Relationships with Large Retailers? An Empirical Investigation of Efficient Consumer Response Adoption. Journal of Marketing, [s. 1.], v. 69, n. 3, p. 80-94, 2005.

DESLAURIERS J. P. Recherche Qualitative. Montreal: McGraw Hill, 1991.

DUSSART, C. Category Management: Strengths, Limits and Developments. European Management Journal, [s. 1.], v. 16, n. 1, p. 50-62, 1998.

ECR BRASIL. Pricewaterhouse Coopers (Cood.). Gerenciamento por Categorias: melhores práticas. São Paulo: Associação ECR Brasil, 1998.

FLAMAND, T. et al. Integrated assortment planning and store-wide shelf space allocation: An optimization-based approach. Omega, [s. 1.], v. 81, p. 134-149, 2018.

GHISI, F. A.; SILVA, A, L. O surgimento e a difusão do Efficient Consumer Response (ECR) na cadeia de suprimentos. Universidade Federal de São Carlos. Pós graduação 
em Engenharia de Produção. Ribeirão Preto/SP: 2008. Disponível em:< http://www.fearp.usp.br/egna/resumos/Ghisi.pdf>. Acesso dia 01 de Junho de 2019.

GOONER, R. A; MORGAN, N. A; PERREAULT JR., W. D. Is Retail category management worth the effort (and does a category captain help or hinder)? Journal of Marketing, 75, n. 5, p. 18-33, 2011.

GUISSONI, L. A; CONSOLI, M. A; CASTRO, L. T. Proposta de gerenciamento por categoria pequeno varejo: do planejamento à virada de loja. In: EMA 2010 - IV Encontro de Marketing da ANPAD, 2010, Florianópolis. Anais. Florianópolis: ANPAD, 2010.

GUISSONI, L. A. et al. Is category management in small supermarkets worth the effort? RAE Revista de Administração de Empresas, Fundação Getúlio Vargas, São Paulo, vol. 53, n. 6, p. 592-603, nov-dez de 2013.

HAMISTER, J. W.; FORTSCH, S. M. Cumulative impact of category management on small retailers. International Journal of Retail \& Distribution Management, [s. 1.], v. 44, n. 7, p. 680-693, 2016.

HONG, S.; MISRA, K.; VILCASSIM, N. J. The Perils of Category Management: The Effect of Product Assortment on Multicategory Purchase Incidence. Journal of Marketing, [s. 1.], v. 80, n. 5, p. 34-10, 2016.

HÜBNER, A. H.; KUHN, H. Retail category management: State-of-the-art review of quantitative research and software applications in assortment and shelf space management. Omega, [s. 1.], v. 40, n. 2, p. 199-209, 2012.

KURTULUS M.; NAKKAS, A.; ÜLKÜ, S. The Value of Category Captainship in the Presence of Manufacturer Competition. Production \& Operations Management, [s. 1.], v. 23, n. 3, p. 420-430, 2014.

LINDBLOM, A.; OLKKONEN, R. An analysis of suppliers' roles in category management collaboration. Journal of Retailing \& Consumer Services, [s. 1.], v. 15, n. 1, p. 1-8, 2008.

MUSALEM, A.; ABURTO, L.; BOSCH, M. Market basket analysis insights to support category management. European Journal of Marketing, [s. 1.], v. 52, n. 7/8, p. 1550$1573,2018$.

NIELSEN. Nielsen Category Management: Positioning Your Organization to Win. NTC Business Books, p. 172, 1992.

PARENTE, J. ; BARKI, E.. Varejo no Brasil. 1. ed. São Paulo: 2014. v. 1. 440p.

PIZZI, G.; SCARPI, D. The effect of shelf layout on satisfaction and perceived assortment size: An empirical assessment. Journal of Retailing \& Consumer Services, [s. 1.], v. 28, p. 67-77, 2016.

SHAAL, K.; HÜBNER, A. When does cross-space elasticity matter in shelf-space planning? A decision analytics approach. Omega, [s. 1.], v. 80, p. 135-152, 2018. 